\title{
Methylammonium tin iodide perovskite: structural, electronic and thermodynamic properties by a DFT study with different exchange-correlation functionals
}

\author{
Catherine Paschal ${ }^{1,3}$ - Alexander Pogrebnoi ${ }^{1} \cdot$ Tatiana Pogrebnaya $^{1} \cdot$ Nicola Seriani $^{2}$
}

Received: 21 January 2020 / Accepted: 16 March 2020 / Published online: 20 March 2020

(c) Springer Nature Switzerland AG 2020

\begin{abstract}
Lead-free perovskites have drawn much attention of researchers in the field of electronics and photovoltaics due to the toxicity issue of the lead halide perovskites. The methylammonium tin iodide $\mathrm{CH}_{3} \mathrm{NH}_{3} \mathrm{Snl}_{3}$ amongst others has become a viable alternative due to its eco-friendliness, as well as narrower bandgap and its wider visible absorption spectrum. In this study different theoretical approaches were employed in investigating the structural, electronic and thermodynamic properties of the orthorhombic phase (O-phase) of the $\mathrm{CH}_{3} \mathrm{NH}_{3} \mathrm{Snl}_{3}$ perovskite. By using the first-principle calculations with the density functional theory, a direct bandgap was determined at gamma symmetry points with three exchangecorrelation functionals: PBE $1.12 \mathrm{eV}$, PBEsol $0.98 \mathrm{eV}$, and LDA $0.46 \mathrm{eV}$. Based on the comparison of lattice constants and bandgaps with the experimental values, the best performance resulted from PBE. The decomposition of the $\mathrm{CH}_{3} \mathrm{NH}_{3} \mathrm{Snl}_{3}$ perovskite into solid state products, $\mathrm{CH}_{3} \mathrm{NH}_{3} \mathrm{l}$ and $\mathrm{Snl}_{2}$, was considered; the enthalpy of the reaction $\Delta_{\mathrm{r}} \mathrm{H}^{\circ}(0 \mathrm{~K})=37 \mathrm{~kJ} \mathrm{~mol}^{-1}$ and enthalpy of formation of the O-phase perovskite $\Delta_{\mathrm{f}} \mathrm{H}^{\circ}\left(\mathrm{CH}_{3} \mathrm{NH}_{3} \mathrm{Snl}_{3}, 0 \mathrm{~K}\right)=-390 \mathrm{~kJ} \mathrm{~mol}^{-1}$ were evaluated, indicating the stability of the O-phase $\mathrm{CH}_{3} \mathrm{NH}_{3} \mathrm{Snl}_{3}$ at low temperature, in agreement with experimental findings.
\end{abstract}

Keywords Tin perovskite · Orthorhombic · Quantum ESPRESSO · PBE · PBEsol · Enthalpy of formation

\section{Introduction}

The rate of population growth and increase in industrialization are reflected in the energy demand for day-to-day activities. Due to the number of years required to replenish the fossil fuels and the effects they pose to the environment, the search for viable renewable energy resources is of very importance. Solar energy is one of the most promising sources due to its availability. Currently, our market is dominated by silicon solar cells. These cells are suffering from the high cost in production and installation which leads to a long payback time in many areas and hence in one way or another tends to lower their widespread use.
Efforts have been made to find cheaper materials to replace silicon. Perovskite materials have recently gained popularity due to their higher power conversion efficiency (PCE) as compared to silicon [1-3]. The term 'organicmetal-halide pervoskites' describes materials of the formula $A B X_{3}$ where $A$ stands for an organic cation, $B$ for metal ion and $\mathrm{X}$ is a halide $(\mathrm{Cl}, \mathrm{Br}, \mathrm{I})$. The hybrid perovskites are peculiar due to their lower cost, possession of strong optical absorption, high charge carrier mobility, and low temperature vapor assisted solution based processing; the cells based on perovskites have also a high power conversion efficiency, a good potential to attain a stable structure with long carrier-diffusion length [4-6]. Kojima et al. [7] were the first who reported that perovskites solar cells

Catherine Paschal, catherinep@nm-aist.ac.tz| ${ }^{1}$ Department of Materials, Energy Science and Engineering, The Nelson Mandela African Institution of Science and Technology, Arusha, United Republic of Tanzania. ${ }^{2}$ The Abdus Salam International Centre for Theoretical Physics, Strada Costiera 11, 34151 Trieste, Italy. ${ }^{3}$ Department of Science, Mwenge Catholic University, Moshi, United Republic of Tanzania. 
possess as high PCE as 3.9\%. Later it was reported on even greater efficiencies of lead perovskite solar cells: $6.5 \%$ [8], $17.9 \%$ [9-11] then to over $22.7 \%$ [12-14].

Lead perovskite materials have drawn significant attention of researchers because of the high ability to convert the energy from the sun to electricity as compared to silicon materials. In the other fields of research, the perovskites have been widely applied in electrodes [15], high temperature superconductors [16], wearable electronics [17], optoelectronics (sensors, LEDs) [16, 18], fuel cells and as oxygen carriers $[19,20]$ and thermoelectric materials [21]. The toxicity issue of lead among other issues has been a challenge in commercializing the lead perovskites and so banned from numerous technical applications in many countries $[13,22]$. Alternatives to $\mathrm{Pb}$, such as $\mathrm{Sn}, \mathrm{Ge}, \mathrm{Cu}, \mathrm{Bi}$, and $\mathrm{Sb}$, have been explored $[9,13,22]$. Tin-based perovskites have shown excellent mobility in transistors [23] which gives them an opportunity to be explored more for solar cell applications. Both tin and lead belong to the same group all having similar valence configuration. Tin has shown some exceptional properties like having a smaller effective mass of holes as compared to lead and narrower bandgap which is useful in more photons absorption $[24,25]$. A study by Umari and coworkers [25] has shown that $\mathrm{CH}_{3} \mathrm{NH}_{3} \mathrm{Snl}_{3}$ has high potential in delivering high photocurrent density due to its reduced band gap when compared to $\mathrm{CH}_{3} \mathrm{NH}_{3} \mathrm{Pbl}_{3}$.

Different phases of the $\mathrm{CH}_{3} \mathrm{NH}_{3} \mathrm{Snl}_{3}$ perovskite have been investigated including the cubic [22, 26-29], tetragonal $[9,19,25,26,30,31]$ and orthorhombic (O-phase) [32-34]. From the experimental data, the phase transitions are discovered through the temperature dependence of the single-crystal resistivity [35] as well as from the photoluminescence and absorption spectra measured in the temperature range between 8 and $295 \mathrm{~K} \mathrm{[36],} \mathrm{the} \mathrm{CH}_{3} \mathrm{NH}_{3} \mathrm{Snl}_{3}$ phase transitions occur at $\sim 110 \mathrm{~K}, \mathrm{O}-$ phase to tetragonal, and at $\sim 275 \mathrm{~K}$, tetragonal to cubic.

The characteristics of each phase are of importance because of phase transformations in the perovskite when subjected to different temperatures as observed for the methylammonium lead perovskite [36-41]. This study aimed at investigation of structural, electronic and thermodynamic properties of the O-phase of the methylammonium tin perovskite using different theoretical approaches to understand the photovoltaic performance of the material. The O-phase was chosen due to the results of the experimental study by Peng and $\mathrm{Xu}$ [24] that the power conversion efficiency of the O-phase $\mathrm{CH}_{3} \mathrm{NH}_{3} \mathrm{Snl}_{3}$ solar cells was higher compared to that of the tetragonal.

\section{Methodology}

Simulation of methylammonium tin iodide $\left(\mathrm{CH}_{3} \mathrm{NH}_{3} \mathrm{Snl}_{3}\right)$ was done using the Quantum ESPRESSO Software package (QE) [42]. The Crystallographic Information Files of $\mathrm{CH}_{3} \mathrm{NH}_{3} \mathrm{Snl}_{3}$ were obtained from the Crystallography Open Database [43, 44] and Materials Project [45] which are free databases for crystal structures. The input files for $Q E$ were generated as described by the software manual [42]. The initial data for this simulation were generated through convergence tests on the structure done by self-consistent field (SCF) calculations to determine the convergence of the plane wave cut-off (ecutwfc), lattice parameters as well as the charge density cut-off (ecutrho) with the total energy. The ultrasoft pseudopotentials were employed with three different exchange-correlation (XC) functionals, i.e. Perdew, Burke and Ernzerhof (PBE) [46], Local Density Approximation (LDA) [47], and Perdew-Burke-Ernzerhof revised for solids (PBEsol) [48]. The ecutwfc and ecutrho were obtained through convergence tests as 50 with $450 \mathrm{Ry}, 60$ with 600 Ry and 70 with 490 Ry, for the LDA, PBE, and PBEsol functionals, respectively.

Brillouin zone sampling was performed as described by Hinuma et al. [49] and Setyawan and Curtarolo [50] for orthorhombic structures. The cell relaxation (cell optimization) was conducted as described by the Quantum ESPRESSO input file $[42,51]$ following the Broyden-Fletcher-Goldfarb-Shanno algorithm. The cell parameters and atomic positions of the structure were relaxed with each $X C$ functional to a force convergence threshold of 1.0E-04 Ry/Bohr and energy convergence threshold of 1.0E-08 Ry which were enough to obtain a relaxed structure $[42,51]$. Additionally, the ultrasoft pseudopotentials from QE database corresponding to the three exchange-correlation functionals (LDA, PBE, and PBEsol) were used for the band structures and density of states calculation.

\section{Results and discussion}

\subsection{Structural parameters}

An orthorhombic phase of $\mathrm{CH}_{3} \mathrm{NH}_{3} \mathrm{Snl}_{3}$ with 48 atoms per cell was considered. Both the original structure from the database (before optimization) and optimized structures were simulated using the same values for ecutwfc and ecutrho to check the relevance of optimizing structures before simulation. The software, VESTA [52] and XCrySDen [53] were used to view the structures before 


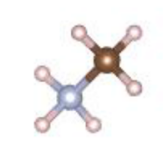

$\left[\mathrm{CH}_{3} \mathrm{NH}_{3}\right]^{+}$

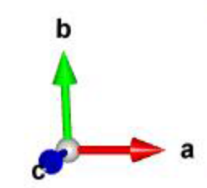

(a)

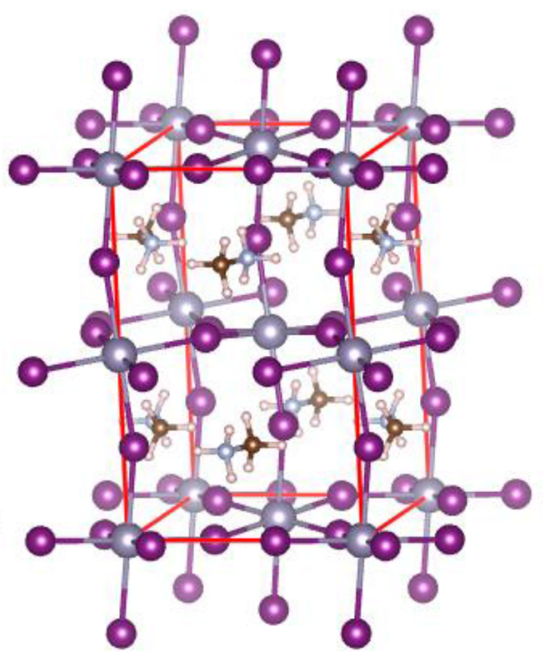

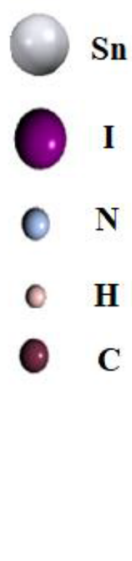

(b)

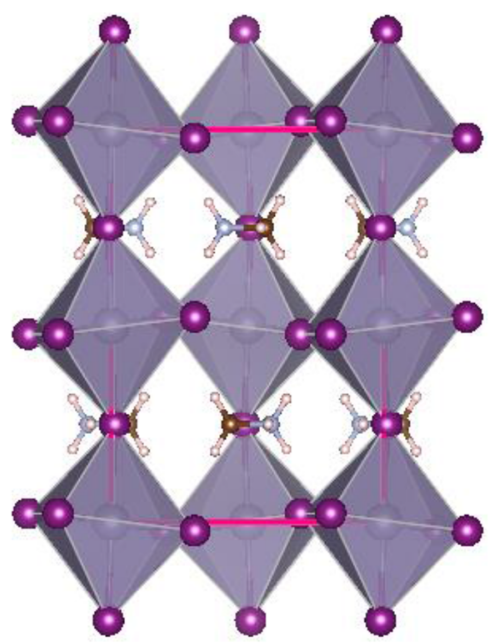

Fig. 1 The unit cell of the orthorhombic phase of $\mathrm{CH}_{3} \mathrm{NH}_{3} \mathrm{Snl}_{3}$ visualization by VESTA [52] as balls and sticks (a) and polyhedral style (b)

Table 1 The calculated lattice parameters and energy gap of the orthorhombic phase of $\mathrm{CH}_{3} \mathrm{NH}_{3} \mathrm{Snl}_{3}$ hybrid halide perovskite

\begin{tabular}{|c|c|c|c|c|c|c|}
\hline \multicolumn{3}{|c|}{ Lattice parameters $(\AA ̊)$} & \multirow[t]{2}{*}{ Volume $\left(\AA^{3}\right)$} & \multirow[t]{2}{*}{$E_{g}(e V)$} & \multirow[t]{2}{*}{ XC functional } & \multirow[t]{2}{*}{ References } \\
\hline a & $\mathrm{b}$ & c & & & & \\
\hline \multirow[t]{2}{*}{8.505} & \multirow[t]{2}{*}{13.156} & \multirow[t]{2}{*}{9.149} & \multirow[t]{2}{*}{1023.70} & 0.88 & PBE & This work ${ }^{a}$ \\
\hline & & & & 0.82 & PBEsol & This work ${ }^{\mathrm{a}}$ \\
\hline 8.500 & 12.880 & 9.120 & 998.46 & 0.46 & LDA & This work $^{\mathrm{b}}$ \\
\hline 8.490 & 13.020 & 9.150 & 1011.44 & 1.12 & PBE & This work ${ }^{b}$ \\
\hline 8.500 & 13.000 & 9.140 & 1009.97 & 0.98 & PBEsol & This work ${ }^{b}$ \\
\hline 8.556 & 12.428 & 8.326 & 885.34 & 1.70 & HSE06 & {$[54]$} \\
\hline 8.56 & 12.41 & 8.43 & 895.52 & 1.27 & HSE06 & {$[34]$} \\
\hline \multirow[t]{2}{*}{8.83} & \multirow[t]{2}{*}{12.68} & \multirow[t]{2}{*}{8.51} & \multirow[t]{2}{*}{952.82} & 0.60 & $\operatorname{PBE}(G G A)$ & {$[24]$} \\
\hline & & & & 0.94 & PBE & {$[32]$} \\
\hline
\end{tabular}

${ }^{a} E_{g}$ calculated with original lattice parameters taken from the database $[44,45]$

${ }^{b} E_{g}$ calculated with optimized parameters and after optimization. The structure contains a network of corner-sharing of [ $\left.\mathrm{Snl}_{6}\right]$ octahedrons with the Snsite cations and iodide anions, and the organic cation $\left[\mathrm{CH}_{3} \mathrm{NH}_{3}\right]^{+}$which is located in between the octahedral corners (Fig. 1). The lattice parameters before and after optimization are compared as listed in Table 1. There was no noticeable deformation of the structures during the structural relaxation, only a slight change can be observed on the lattice parameters and volume of the cell.

The relationship between the energy and volume of the orthorhombic perovskite cell is represented by the energy-volume diagram (Fig. 2); the PBE XC functional results to the minimum energy at the volume 1011.44 $\AA^{3}$ (Table 1).

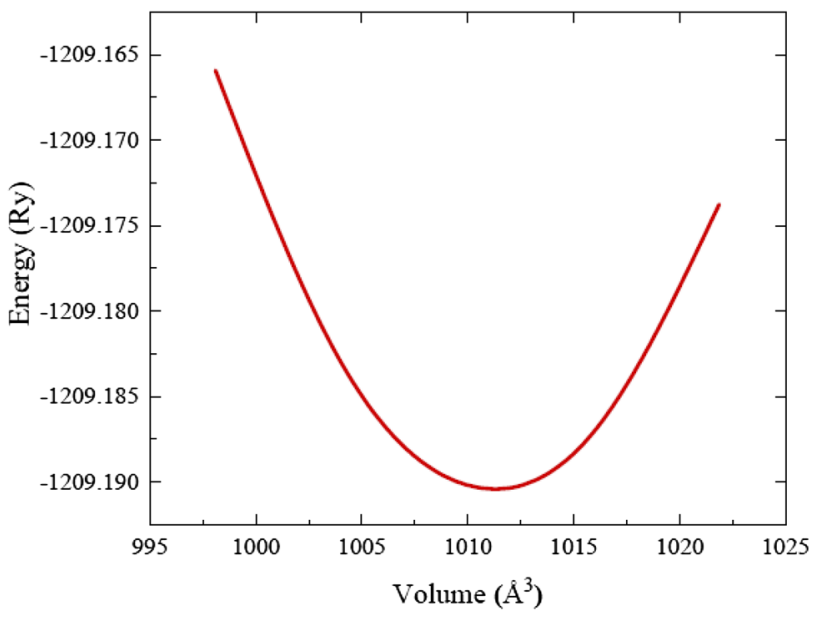

Fig. 2 Energy-volume diagram for the orthorhombic $\mathrm{CH}_{3} \mathrm{NH}_{3} \mathrm{Snl}_{3}$ cell using PBE 


\subsection{Electronic properties}

The electronic structures of the hybrid halide perovskites are of crucial factors that need to be explored because these materials have the potential application as a lightharvesting medium. The calculated band structures of the non-optimized and optimized orthorhombic $\mathrm{CH}_{3} \mathrm{NH}_{3} \mathrm{Snl}_{3}$ crystals along the high-symmetry lines in the first Brillouin zone are presented in Figs. 3, 4, 5 and 6.

The orthorhombic crystal has a direct bandgap at $\Gamma$ symmetry points with different calculated bandgap energies from the LDA, PBE, and PBEsol DFT functionals. The Fermi levels for the three exchange-correlation functionals are all located between the valence band maxima and the conduction band minima of the material. They were tuned to zero at the valence band maxima for proper visualization of the bandgap. As is seen, the different values of $E_{g}$ result from the $L D A, P B E$, and PBEsol DFT functionals. The bandgap energies for the optimized $\mathrm{CH}_{3} \mathrm{NH}_{3} \mathrm{Snl}{ }_{3}$ structure, to the best accuracy of the $\mathrm{XC}$ functionals, are obtained: $1.12 \mathrm{eV}$ (PBE) and $0.98 \mathrm{eV}$ (PBEsol), which are comparable to the experimental data 1.2-1.35 eV [29, 44]. The LDA functional brings to the $E_{g}=0.46 \mathrm{eV}$ which is much lower than experimental. This result is not surprising because generally, the LDA XC functional from standard DFT has been found to underestimate the bandgap energies of solid-state semiconductors and insulators by about $40 \%[55,56]$ which originates from assigning physical meaning to the Kohn-Sham energy levels rather than from intrinsic errors of the DFT methods [57]. For the nonoptimized O-phase, the PBE and PBEsol functionals result in the bandgaps $0.88 \mathrm{eV}$ and $0.82 \mathrm{eV}$, respectively, these values are substantially underestimated that apparently indicates the need to relax the crystal structure before calculating electronic properties. It is interesting to note that other DFT studies $[24,32,34,54]$ of the $\mathrm{CH}_{3} \mathrm{NH}_{3} \mathrm{Snl}_{3}$ orthorhombic structure conducted using different $\mathrm{XC}$ functionals reported bandgap values in a broad range, between 0.6 and $1.7 \mathrm{eV}$ (Table 1).

\subsection{Density of states}

The total projected density of states (TPDOS) and the projected density of states (PDOS) of the orthorhombic $\mathrm{CH}_{3} \mathrm{NH}_{3} \mathrm{Snl}_{3}$ were calculated using the projwfc.x code implemented in the QE package. The PDOS displays the interaction of the orbitals for interpretation of the bonding mechanisms between the atoms in the system (Figs. 3,
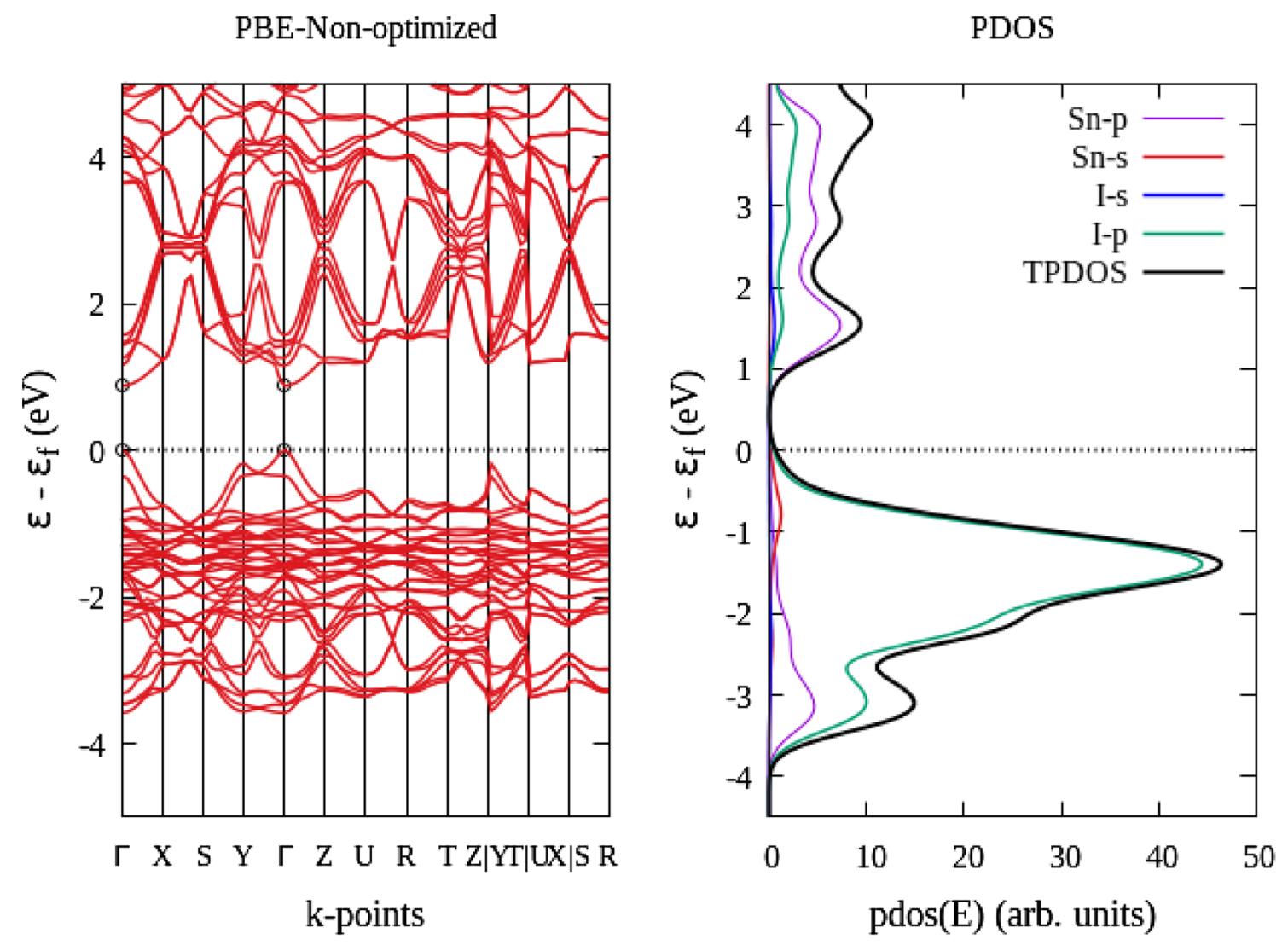

Fig. 3 The band structure and PDOS of original orthorhombic $\mathrm{CH}_{3} \mathrm{NH}_{3} \mathrm{Snl}_{3}$ simulated with the PBE XC functional 

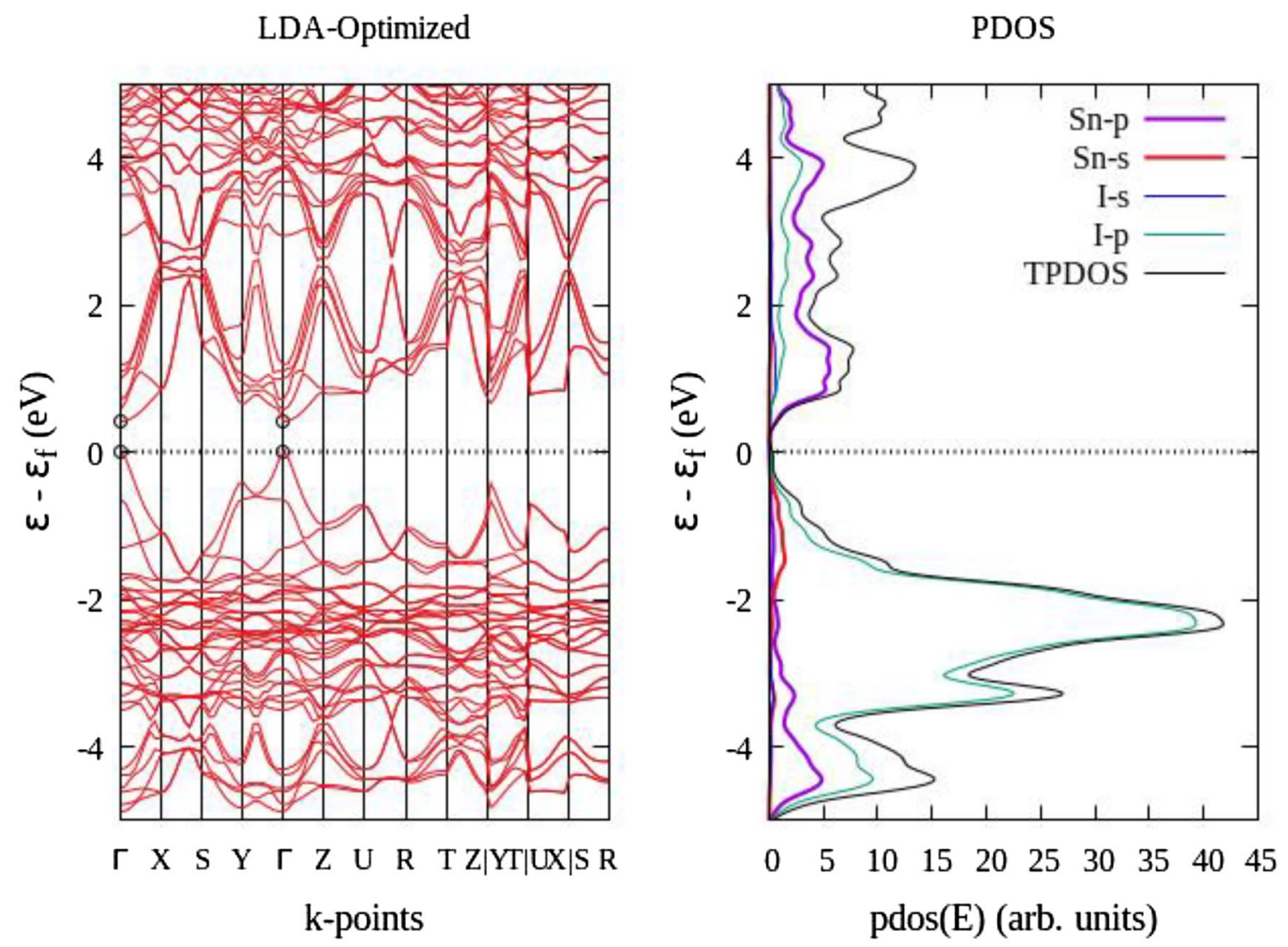

Fig. 4 The band structure and PDOS of optimized orthorhombic $\mathrm{CH}_{3} \mathrm{NH}_{3} \mathrm{Snl}_{3}$ simulated with the LDA XC functional

$4,5,6$, right-hand side). A higher density of states can be seen distributed in the valence band of the perovskite which indicates that the $\mathrm{CH}_{3} \mathrm{NH}_{3} \mathrm{Snl}_{3}$ perovskite belongs to the family of semiconductors. The analysis provides a better understanding of the bandgap variations which is influenced by the electronic states of the $\mathrm{S} n$ and I atoms. The $5 p$-states of the I atoms are the main contributors to the valence band maxima with a slight overlapping with the $5 \mathrm{~s}$-states of tin. On the other hand, the conduction band is populated by the $5 p$-states of $S n$ atoms responsible for formation of the conduction band minima with small contribution from the $5 p$-states of the iodine atoms. In general, the location of the Fermi level in between the valence band and conduction band is governed by the electron density of the $p$-states of tin and iodine atoms in the perovskite.

\subsection{Thermodynamic properties}

The energy of decomposition reaction and enthalpy of formation of photovoltaic materials are essential in determining the stability of materials when subjected to moisture, light, and heat. Both tin and lead halide perovskites basing on methylammonium experience a rapid conversion to the halides under the conditions of high humidity $[58,59]$.

The decomposition of the $\mathrm{CH}_{3} \mathrm{NH}_{3} \mathrm{Snl}_{3}$ into the solid state products may proceed as follows:

$\mathrm{CH}_{3} \mathrm{NH}_{3} \mathrm{Snl}_{3}(\mathrm{~s})=\mathrm{CH}_{3} \mathrm{NH}_{3} \mathrm{I}(\mathrm{s})+\mathrm{Snl}_{2}(\mathrm{~s})$.

The energy of this reaction $\Delta_{\mathrm{r}} E$ was found through the total energies $E$ of the components:

$\Delta_{\mathrm{r}} E=E\left(\mathrm{CH}_{3} \mathrm{NH}_{3} \mathrm{I}\right)+E\left(\mathrm{Snl}_{2}\right)-E\left(\mathrm{CH}_{3} \mathrm{NH}_{3} \mathrm{Snl}_{3}\right)$.

The total energies $E$ were computed for the relaxed structures of the participants using the three DFT XC functionals (Table 2). As is seen, the XC functional affects significantly the calculated values of $\triangle_{\mathrm{r}} E:-22 \mathrm{~kJ} \mathrm{~mol}^{-1}$ (LDA), $37 \mathrm{~kJ} \mathrm{~mol}^{-1}$ (PBE) and $9 \mathrm{~kJ} \mathrm{~mol}^{-1}$ (PBEsol). It is known that the orthorhombic $\mathrm{CH}_{3} \mathrm{NH}_{3} \mathrm{Snl}_{3}$ is stable at temperature below $110 \mathrm{~K}[35,36]$, hence the result from PBE seems most reasonable.

Based on the $\Delta_{\mathrm{r}} E$, the enthalpy of formation of the O-phase perovskite can be determined through the enthalpies of formation of the precursors: 

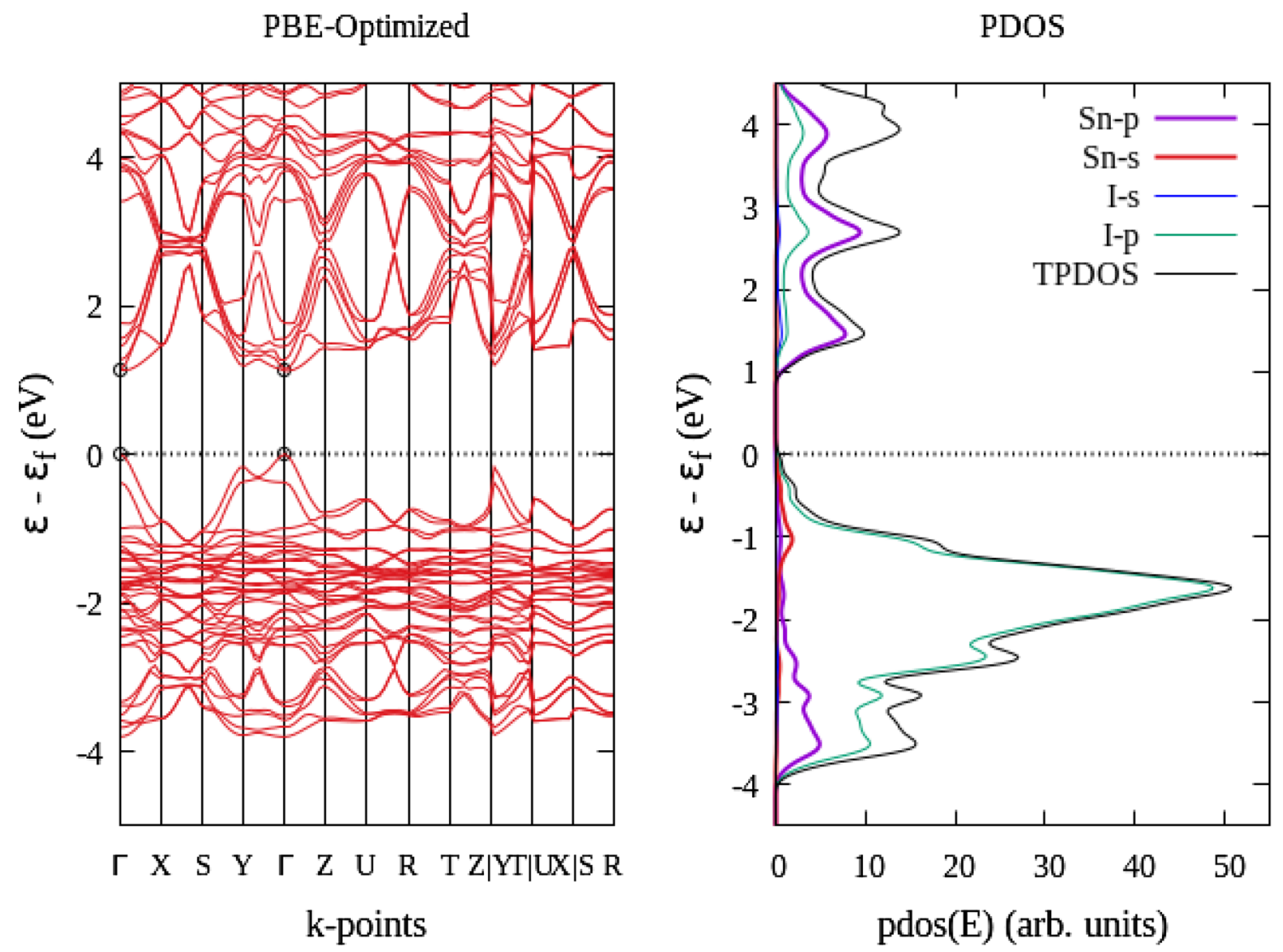

Fig. 5 The band structure and PDOS of optimized orthorhombic $\mathrm{CH}_{3} \mathrm{NH}_{3} \mathrm{Snl}_{3}$ simulated with the PBE XC functional

$$
\begin{aligned}
\Delta_{\mathrm{f}} H^{\circ} & \left(\mathrm{CH}_{3} \mathrm{NH}_{3} \mathrm{Snl}_{3}, \mathrm{~s}, 0 \mathrm{~K}\right) \\
= & \Delta_{\mathrm{f}} H^{\circ}\left(\mathrm{CH}_{3} \mathrm{NH}_{3} \mathrm{l}, \mathrm{s}, 0 \mathrm{~K}\right) \\
& +\Delta_{\mathrm{f}} H^{\circ}\left(\mathrm{Snl}_{2}, \mathrm{~s}, 0 \mathrm{~K}\right)-\Delta_{\mathrm{r}} H^{\circ}(0 \mathrm{~K}) .
\end{aligned}
$$

The reference values are available: $\Delta_{\mathrm{f}} H^{\circ}\left(\mathrm{Snl}_{2}, \mathrm{~s}\right.$, $0 \mathrm{~K})=-152.4 \mathrm{~kJ} \mathrm{~mol}^{-1}$ [60] and $\Delta_{\mathrm{f}} \mathrm{H}^{\circ}\left(\mathrm{CH}_{3} \mathrm{NH}_{3} \mathrm{l}\right.$, s, $298 \mathrm{~K})=-200.7 \mathrm{~kJ} \mathrm{~mol}^{-1}$ [61]. Assuming that correction on lattice vibration energies is negligible for the reaction (1), we accept $\Delta_{\mathrm{r}} H^{\circ}(0 \mathrm{~K}) \approx \Delta_{\mathrm{r}} E$. In addition, we suggest that the enthalpy increment $H^{\circ}(298)-H^{\circ}$ (0) for $\mathrm{CH}_{3} \mathrm{NH}_{3} \mathrm{I}$ does not exceed few $\mathrm{kJ} \mathrm{mol}^{-1}$. Similar assumptions were opinioned by Ciccioli, Latini [62] for the decomposition of lead perovskites $\mathrm{CH}_{3} \mathrm{NH}_{3} \mathrm{PbX}_{3}(\mathrm{~s})=\mathrm{CH}_{3} \mathrm{NH}_{3} \mathrm{X}(\mathrm{s})+\mathrm{Pbl}_{2}(\mathrm{~s})$, $\mathrm{X}=\mathrm{Cl}, \mathrm{Br}$, I. Thus we obtained the enthalpy of formation of the O-phase tin perovskite $\mathrm{CH}_{3} \mathrm{NH}_{3} \mathrm{Snl}_{3}$ (Table 2). As it was discussed in the previous sections, the PBE $X C$ functional outperformed the other two in evaluation of the electronic properties, therefore we consider the $\Delta_{\mathrm{r}} H^{\circ}(0 \mathrm{~K})=37 \mathrm{~kJ} \mathrm{~mol}^{-1}$ and $\Delta_{\mathrm{f}} \mathrm{H}^{\circ}\left(\mathrm{CH}_{3} \mathrm{NH}_{3} \mathrm{Snl}_{3}\right.$, $0 \mathrm{~K})=-390 \mathrm{~kJ} \mathrm{~mol}^{-1}$ to be reliable values.

It is worth to compare these results with the literature data for the lead perovskite. For the tetragonal phase of $\mathrm{CH}_{3} \mathrm{NH}_{3} \mathrm{Pbl}_{3}$, the enthalpy of decomposition reaction
$\Delta_{\mathrm{r}} \mathrm{H}^{\circ}(298 \mathrm{~K})=34.5 \pm 1.0 \mathrm{~kJ} \mathrm{~mol}^{-1}$ was determined by solution calorimetry [59]. Using the enthalpy of formation $\Delta_{\mathrm{f}} H^{\circ}\left(\mathrm{Pbl}_{2}, \mathrm{~s}, 298 \mathrm{~K}\right)=-176 \mathrm{~kJ} \mathrm{~mol}^{-1}[60]$ the enthalpy of formation of the lead perovskite can be found as $\Delta_{\mathrm{f}} \mathrm{H}^{\circ}\left(\mathrm{CH}_{3} \mathrm{NH}_{3} \mathrm{Pbl}_{3}, \mathrm{~s}, 298 \mathrm{~K}\right)=-411 \mathrm{~kJ} \mathrm{~mol}^{-1}$. Taking into account the phase transition enthalpy from tetragonal to orthorhombic $3 \mathrm{~kJ} \mathrm{~mol}^{-1}$ [63] and neglecting the enthalpy increment $H^{\circ}(298)-H^{\circ}(0)$, we estimated the $\Delta_{\mathrm{f}} H^{\circ}$ $\left(\mathrm{CH}_{3} \mathrm{NH}_{3} \mathrm{Pbl}_{3}\right.$, O-phase, $\left.0 \mathrm{~K}\right) \approx-414 \mathrm{~kJ} \mathrm{~mol}^{-1}$. Compared to this value, our result for the enthalpy of formation of the tin perovskite $\left(-390 \mathrm{~kJ} \mathrm{~mol}^{-1}\right)$ is in a good accordance. Moreover, it is interesting to note that the difference in $\Delta_{\mathrm{f}} \mathrm{H}^{\circ}$ between tin and lead perovskites $\left(24 \mathrm{~kJ} \mathrm{~mol}^{-1}\right)$ appeared to be almost equal to that between $\mathrm{Snl}_{2}$ and $\mathrm{Pbl}_{2}$ $\left(23 \mathrm{~kJ} \mathrm{~mol}^{-1}\right)$, this equality also advocates correctness of our result.

\section{Conclusion}

Different exchange-correlation functionals LDA, PBE, and PBEsol have been used to study the structural, electronic and thermodynamic properties of the O-phase of the $\mathrm{CH}_{3} \mathrm{NH}_{3} \mathrm{Snl}_{3}$ perovskite. The PBE XC functional 

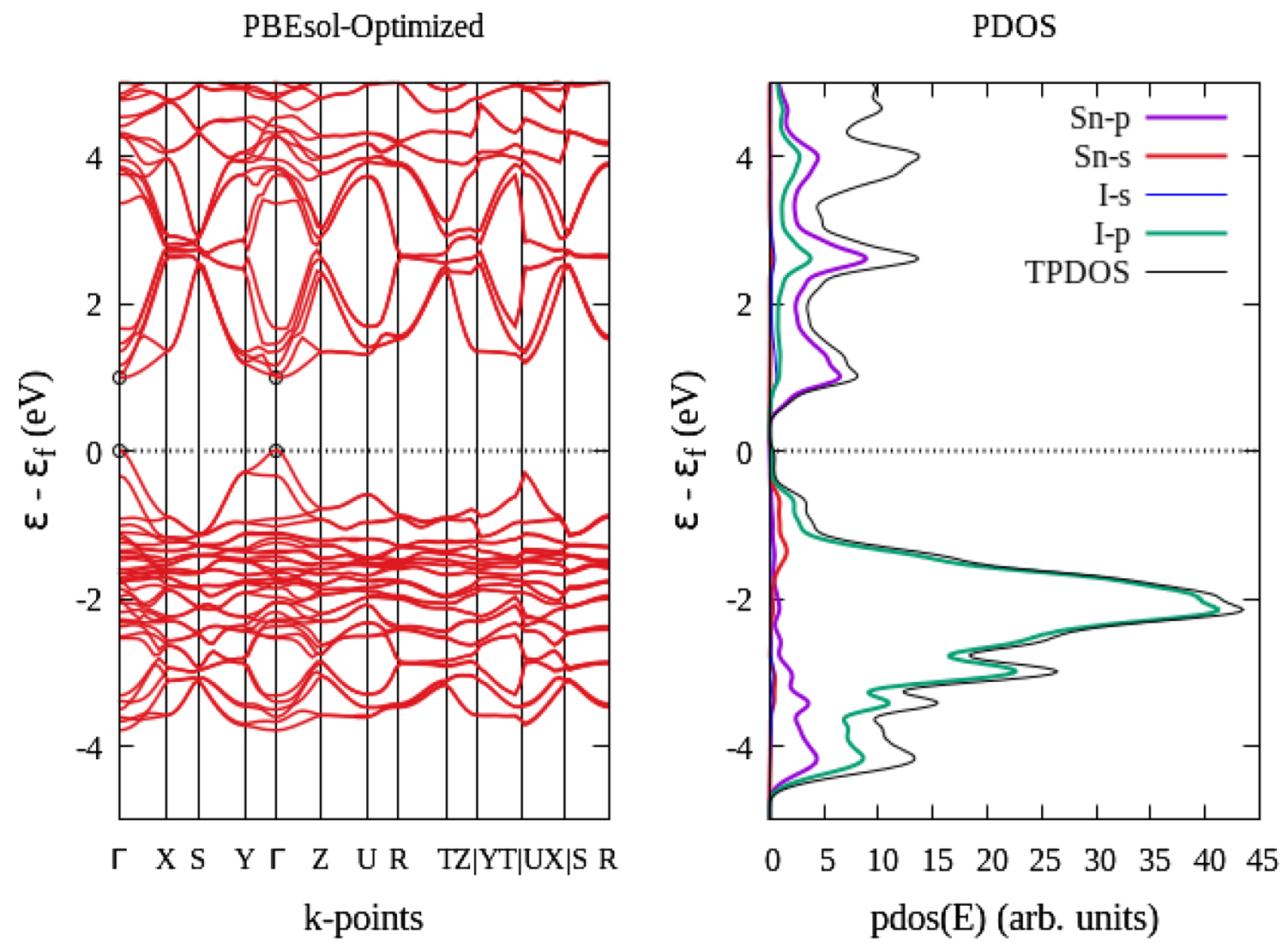

Fig. 6 The band structure and PDOS of optimized orthorhombic simulated with the PBEsol XC functional

Table 2 Thermodynamic characteristics of decomposition reaction (1)

\begin{tabular}{|c|c|c|c|c|c|}
\hline \multirow[t]{2}{*}{ XC functional } & \multicolumn{3}{|l|}{$-E$, Ry } & \multirow{2}{*}{$\begin{array}{l}\Delta_{\mathrm{r}} H^{\circ}(0 \mathrm{~K}), \mathrm{kJ} \\
\mathrm{mol}^{-1}\end{array}$} & \multirow{2}{*}{$\begin{array}{l}-\Delta_{\mathrm{f}} \mathrm{H}^{\circ} \\
\left(\mathrm{CH}_{3} \mathrm{NH}_{3} \mathrm{Snl}_{3}\right. \\
0 \mathrm{~K}), \mathrm{kJ} \mathrm{mol}^{-1}\end{array}$} \\
\hline & $\mathrm{CH}_{3} \mathrm{NH}_{3} \mathrm{Snl}_{3}$ & $\mathrm{CH}_{3} \mathrm{NH}_{3} \mathrm{I}$ & $\mathrm{Snl}_{2}$ & & \\
\hline LDA & 303.095607 & 73.460970 & 229.651248 & -21.8 & 331 \\
\hline PBE & 303.298946 & 73.449692 & 229.821122 & 36.9 & 390 \\
\hline PBEsol & 302.377144 & 72.961524 & 229.408919 & 8.8 & 362 \\
\hline
\end{tabular}

outperformed the LDA and PBEsol in estimating the electronic and thermodynamic properties of the perovskite. It was found that for the optimized structure, the bandgap determined by the PBE XC functional $(1.12 \mathrm{eV})$, was much closer to the experimental value $(1.2 \mathrm{eV})$ when compared to the other two. In addition, importance of the crystal structure relaxation procedure, before calculating electronic properties, was corroborated. From the projected density of states, it is observed that the valence band is mostly occupied with $5 p$-electrons of the iodine atoms and the conduction band with $5 p$-electrons of the tin atoms. Considering the thermodynamic characteristics of the decomposition reaction, the methylammonium tin iodide perovskite is confirmed to be stable material at low temperature that is in accordance with literature data on phase transformations in the crystals.

Acknowledgements The authors thank the African Development Bank (AfDB) for funding this work.

Complaince with ethical standards

Conflict of interest On behalf of all authors, the corresponding author states that there is no conflict of interest. 


\section{References}

1. Candan A, Kurban M (2018) Electronic structure, elastic and phonon properties of perovskite-type hydrides $\mathrm{MgXH}_{3}(\mathrm{X}=\mathrm{Fe}, \mathrm{Co})$ for hydrogen storage. Solid State Commun 281:38-43

2. Kurban M, Kürkçü C, Yamçıçıer Ç, Göktaş F (2019) A study of structural phase transitions and optoelectronic properties of perovskite-type hydride $\mathrm{MgFeH}_{3}$ : ab initio calculations. J Phys Condens Matter 31(30):305401

3. Tai Q, Tang K-C, Yan F (2019) Recent progress of inorganic perovskite solar cells. Energy Environ Sci 12(8):2375-2405

4. Chang JA, Im SH, Lee YH, Kim H-j, Lim C-S, Heo JH, Seok SI (2012) Panchromatic photon-harvesting by hole-conducting materials in inorganic-organic heterojunction sensitized-solar cell through the formation of nanostructured electron channels. Nano Lett 12(4):1863-1867

5. Malinkiewicz O, Yella A, Lee YH, Espallargas GM, Graetzel M, Nazeeruddin MK, Bolink HJ (2014) Perovskite solar cells employing organic charge-transport layers. Nat Photon 8(2):128

6. Yang Z, Wang Y, Liu Y (2018) Stability and charge separation of different $\mathrm{CH}_{3} \mathrm{NH}_{3} \mathrm{Snl}_{3} / \mathrm{TiO}_{2}$ interface: a first-principles study. Appl Surf Sci 441:394-400

7. Kojima A, Teshima K, Shirai Y, Miyasaka T (2009) Organometal halide perovskites as visible-light sensitizers for photovoltaic cells. J Am Chem Soc 131(17):6050-6051

8. Im J-H, Lee C-R, Lee J-W, Park S-W, Park N-G (2011) 6.5\% efficient perovskite quantum-dot-sensitized solar cell. Nanoscale 3(10):4088-4093

9. Noel NK, Stranks SD, Abate A, Wehrenfennig C, Guarnera S, Haghighirad A-A, Sadhanala A, Eperon GE, Pathak SK, Johnston MB (2014) Lead-free organic-inorganic tin halide perovskites for photovoltaic applications. Energy Environ Sci 7(9):3061-3068

10. Lee MM, Teuscher J, Miyasaka T, Murakami TN, Snaith HJ (2012) Efficient hybrid solar cells based on meso-superstructured organometal halide perovskites. Science 338(6107):643-647

11. Noh JH, Im SH, Heo JH, Mandal TN, Seok SI (2013) Chemical management for colorful, efficient, and stable inorganic-organic hybrid nanostructured solar cells. Nano Lett 13(4):1764-1769

12. Hoefler SF, Trimmel G, Rath T (2017) Progress on lead-free metal halide perovskites for photovoltaic applications: a review. Chem Mon 148(5):795-826

13. Jiang F, Yang D, Jiang Y, Liu T, Zhao X, Ming Y, Luo B, Qin F, Fan $J$, Han H (2018) Chlorine-incorporation-induced formation of the layered phase for antimony-based lead-free perovskite solar cells. J Am Chem Soc 140(3):1019-1027

14. Ono LK, Qi Y (2018) Research progress on organic-inorganic halide perovskite materials and solar cells. J Phys D Appl Phys 51(9):093001

15. Khandy SA, Gupta DC (2017) Investigation of structural, magneto-electronic, and thermoelectric response of ductile $\mathrm{SnAlO}_{3}$ from high-throughput DFT calculations. Int J Quantum Chem 117(8):e25351

16. Frohna K, Stranks SD (2019) Hybrid perovskites for device applications. In: Handbook of organic materials for electronic and photonic devices. Elsevier, pp 211-256

17. Shi B, Duan L, Zhao Y, Luo J, Zhang X (2020) Semitransparent perovskite solar cells: from materials and devices to applications. Adv Mater 32(3):1806474

18. Khandy SA, Gupta DC (2016) Structural, elastic and thermoelectronic properties of paramagnetic perovskite $\mathrm{PbTaO}_{3}$. RSC Adv 6(53):48009-48015

19. Guo X, Zhang B, Lin Z, Su J, Yang Z, Zhang C, Chang J, Liu S, Hao $Y$ (2018) High efficient perovskite solar cells based on dopantfree conjugated DPP polymer hole transport layer: influence of solvent vapor annealing. Sustain Energy Fuels 2(10):2154-2159
20. Vieten J, Bulfin B, Huck P, Horton M, Guban D, Zhu L, Lu Y, Persson KA, Roeb M, Sattler C (2019) Materials design of perovskite solid solutions for thermochemical applications. Energy Environ Sci 12(4):1369-1384

21. Khandy SA, Gupta DC (2017) Electronic structure, magnetism and thermoelectricity in layered perovskites: $\mathrm{Sr}_{2} \mathrm{SnMnO}_{6}$ and $\mathrm{Sr}_{2} \mathrm{SnFeO}_{6}$. J Magn Magn Mater 441:166-173

22. Zhao X-G, Yang J-H, Fu Y, Yang D, Xu Q, Yu L, Wei S-H, Zhang L (2017) Design of lead-free inorganic halide perovskites for solar cells via cation-transmutation. J Am Chem Soc 139(7):2630-2638

23. Kagan C, Mitzi D, Dimitrakopoulos C (1999) Organic-inorganic hybrid materials as semiconducting channels in thin-film fieldeffect transistors. Science 286(5441):945-947

24. Peng $L, X u L$ (2018) Theoretical and experimental research base on the tin iodide organic-inorganic hybrid perovskite $\left(\mathrm{CH}_{3} \mathrm{NH}_{3} \mathrm{Snl}_{3}\right)$ tetragonal and orthorhombic phases for photovoltaics. Sci Adv Mater 10(10):1519-1527

25. Umari P, Mosconi E, De Angelis F (2014) Relativistic GW calculations on $\mathrm{CH}_{3} \mathrm{NH}_{3} \mathrm{Pbl}_{3}$ and $\mathrm{CH}_{3} \mathrm{NH}_{3} \mathrm{Snl}_{3}$ perovskites for solar cell applications. Sci Rep 4:4467

26. Yamada K, Nakada K, Takeuchi Y, Nawa K, Yamane Y (2011) Tunable perovskite semiconductor $\mathrm{CH}_{3} \mathrm{NH}_{3} \mathrm{SnX} \mathrm{X}_{3}(\mathrm{X}: \mathrm{Cl}, \mathrm{Br}$, or I) characterized by X-ray and DTA. Bull Chem Soc Jpn 84(9):926-932

27. Takahashi $Y$, Obara R, Lin Z-Z, Takahashi Y, Naito T, Inabe T, Ishibashi S, Terakura K (2011) Charge-transport in tin-iodide perovskite $\mathrm{CH}_{3} \mathrm{NH}_{3} \mathrm{Snl}_{3}$ : origin of high conductivity. Dalton Trans 40(20):5563-5568

28. Bernal C, Yang K (2014) First-principles hybrid functional study of the organic-inorganic perovskites $\mathrm{CH}_{3} \mathrm{NH}_{3} \mathrm{SnBr}_{3}$ and $\mathrm{CH}_{3} \mathrm{NH}_{3} \mathrm{Snl}_{3}$. J Phys Chem C 118(42):24383-24388

29. Huang Y, Su J, Li Q, Wang D, Xu L, Bai Y (2019) Structure, optical and electrical properties of $\mathrm{CH}_{3} \mathrm{NH}_{3} \mathrm{Snl}_{3}$ single crystal. Physica B 563:107-112

30. Hao F, Stoumpos CC, Cao DH, Chang RP, Kanatzidis MG (2014) Lead-free solid-state organic-inorganic halide perovskite solar cells. Nat Photon 8(6):489

31. Weiss M, Horn J, Richter C, Schlettwein D (2016) Preparation and characterization of methylammonium tin iodide layers as photovoltaic absorbers. phys status solidi (a) 213(4):975-981

32. Suhaili N, Taib MFM, Yaakob MK, Hassan OH, Yahya M (2017) Properties of lead-free hybrid organic-inorganic halide perovskite $\mathrm{CH}_{3} \mathrm{NH}_{3} \mathrm{BX}_{3}$ using density functional theory. Mater Today Proc 4(4):5154-5160

33. Feng J, Xiao B (2014) Crystal structures, optical properties, and effective mass tensors of $\mathrm{CH}_{3} \mathrm{NH}_{3} \mathrm{PbX}_{3}(\mathrm{X}=\mathrm{I}$ and $\mathrm{Br}$ ) phases predicted from HSE06. J Phys Chem Lett 5(7):1278-1282

34. Wu L-J, Zhao Y-Q, Chen C-W, Wang L-Z, Liu B, Cai M-Q (2016) First-principles hybrid functional study of the electronic structure and charge carrier mobility in perovskite $\mathrm{CH}_{3} \mathrm{NH}_{3} \mathrm{Snl}_{3}$. Chin Phys B 25(10):107202

35. Takahashi $Y$, Hasegawa $\mathrm{H}$, Takahashi $Y$, Inabe $\mathrm{T}$ (2013) Hall mobility in tin iodide perovskite $\mathrm{CH}_{3} \mathrm{NH}_{3} \mathrm{Snl}_{3}$ : evidence for a doped semiconductor. J Solid State Chem 205:39-43

36. Parrott ES, Milot RL, Stergiopoulos T, Snaith HJ, Johnston MB, Herz LM (2016) Effect of structural phase transition on chargecarrier lifetimes and defects in $\mathrm{CH}_{3} \mathrm{NH}_{3} \mathrm{Snl}_{3}$ perovskite. J Phys Chem Lett 7(7):1321-1326

37. Kawamura $Y$, Mashiyama $H$, Hasebe $K$ (2002) Structural study on cubic-tetragonal transition of $\mathrm{CH}_{3} \mathrm{NH}_{3} \mathrm{Pbl}_{3}$. J Phys Soc Jpn 71(7):1694-1697

38. Whitfield P, Herron N, Guise W, Page K, Cheng Y, Milas I, Crawford M (2016) Structures, phase transitions and tricritical behavior of the hybrid perovskite methyl ammonium lead iodide. Sci Rep 6:35685

39. Whitfield P, Herron N, Guise W, Page K, Cheng Y, Milas I, Crawford M (2017) Corrigendum: structures, phase transitions and 
tricritical behavior of the hybrid perovskite methyl ammonium lead iodide. Sci Rep 7:42831

40. Bischak CG, Hetherington $\mathrm{CL}$, Wu H, Aloni S, Ogletree DF, Limmer DT, Ginsberg NS (2017) Origin of reversible photoinduced phase separation in hybrid perovskites. Nano Lett 17(2):1028-1033

41. Borriello I, Cantele G, Ninno D (2008) Ab initio investigation of hybrid organic-inorganic perovskites based on tin halides. Phys Rev B 77(23):235214

42. Giannozzi $P$, Andreussi $O$, Brumme $T$, Bunau O, Nardelli MB, Calandra M, Car R, Cavazzoni C, Ceresoli D, Cococcioni M (2017) Advanced capabilities for materials modelling with Quantum ESPRESSO. J Phys Condens Matter 29(46):465901

43. Gražulis $S$, Chateigner D, Downs RT, Yokochi A, Quirós M, Lutterotti L, Manakova E, Butkus J, Moeck P, Le Bail A (2009) Crystallography open database-an open-access collection of crystal structures. J Appl Crystallogr 42(4):726-729

44. Stoumpos CC, Malliakas CD, Kanatzidis MG (2013) Semiconducting tin and lead iodide perovskites with organic cations: phase transitions, high mobilities, and near-infrared photoluminescent properties. Inorg Chem 52(15):9019-9038

45. Jain A, Ong SP, Hautier G, Chen W, Richards WD, Dacek S, Cholia S, Gunter D, Skinner D, Ceder G (2013) Commentary: The materials project: a materials genome approach to accelerating materials innovation. Appl Mater 1(1):011002

46. Perdew JP, Burke K, Ernzerhof M (1996) Generalized gradient approximation made simple. Phys Rev Lett 77(18):3865

47. Ceperley D, Alder B (1980) Exchange-correlation potential and energy for density-functional calculation. Phys Rev Lett 45:567-581

48. Perdew JP, Ruzsinszky A, Csonka Gl, Vydrov OA, Scuseria GE, Constantin LA, Zhou X, Burke K (2008) Restoring the densitygradient expansion for exchange in solids and surfaces. Phys Rev Lett 100(13):136406

49. Hinuma Y, Pizzi G, Kumagai Y, Oba F, Tanaka I (2017) Band structure diagram paths based on crystallography. Comput Mater Sci 128:140-184

50. Setyawan W, Curtarolo S (2010) High-throughput electronic band structure calculations: challenges and tools. Comput Mater Sci 49(2):299-312

51. Giannozzi P, Baroni S, Bonini N, Calandra M, Car R, Cavazzoni C, Ceresoli D, Chiarotti GL, Cococcioni M, Dabo I (2009) QUANTUM ESPRESSO: a modular and open-source software project for quantum simulations of materials. J Phys Condens Matter 21(39):395502

52. Momma K, Izumi F (2008) VESTA: a three-dimensional visualization system for electronic and structural analysis. J Appl Crystallogr 41(3):653-658
53. Kokalj A (1999) XCrySDen-a new program for displaying crystalline structures and electron densities. J Mol Graph Modell 17(3-4):176-179

54. Feng J, Xiao B (2014) Effective masses and electronic and optical properties of nontoxic $\mathrm{MASnX}_{3}(\mathrm{X}=\mathrm{Cl}, \mathrm{Br}$, and I) perovskite structures as solar cell absorber: a theoretical study using HSE06. J Phys Chem C 118(34):19655-19660

55. Perdew JP, Zunger A (1981) Self-interaction correction to density-functional approximations for many-electron systems. Phys Rev B 23(10):5048

56. Perdew JP, Yang W, Burke K, Yang Z, Gross EK, Scheffler M, Scuseria GE, Henderson TM, Zhang IY, Ruzsinszky A (2017) Understanding band gaps of solids in generalized Kohn-Sham theory. Proc Natl Acad Sci 114(11):2801-2806

57. An M-G, Valero R, Illas F (2017) An empirical, yet practical way to predict the band gap in solids by using density functional band structure calculations. J Phys Chem C 121(34):18862-18866

58. Zhao X, Park N-G (2015) Stability issues on perovskite solar cells. In: Photonics, vol 4. Multidisciplinary Digital Publishing Institute, pp 1139-1151

59. Nagabhushana G, Shivaramaiah R, Navrotsky A (2016) Direct calorimetric verification of thermodynamic instability of lead halide hybrid perovskites. Proc Natl Acad Sci 113(28):7717-7721

60. Gurvich L, Yungman V, Bergman G, Veitz I, Gusarov A, lorish V, Leonidov VY, Medvedev V, Belov G, Aristova N (1992) Thermodynamic properties of individual substances. Ivtanthermo for windows database on thermodynamic properties of individual substances and thermodynamic modeling software, vol Version 3.0 Glushko Thermocenter of RAS, Moscow

61. Wilson JW (1976) Standard enthalpies of formation and thermodynamic cycle values of crystal lattice energies of methylammonium halides. J Chem Soc Dalton Trans 10:890-893

62. Ciccioli A, Latini A (2018) Thermodynamics and the intrinsic stability of lead halide perovskites $\mathrm{CH}_{3} \mathrm{NH}_{3} \mathrm{PbX}_{3}$. J Phys Chem Lett 9(13):3756-3765

63. Onoda-Yamamuro N, Matsuo T, Suga H (1990) Calorimetric and IR spectroscopic studies of phase transitions in methylammonium trihalogenoplumbates (II). J Phys Chem Solids 51(12):1383-1395

Publisher's Note Springer Nature remains neutral with regard to jurisdictional claims in published maps and institutional affiliations. 